\title{
Changes in Ocular Higher-Order Aberrations after Corneal Collagen Cross-Linking for Keratoconus
}

\author{
AHMED M. MOHARAM, M.Sc.; MOHAMED M. KHATER, M.D.; \\ HISHAM A. SAAD, M.D., F.R.C.S. (GLASG.) and KHALED A. NAGY, M.D. \\ The Department of Ophthalmology, Faculty of Medicine, Tanta University, Tanta, Egypt
}

\begin{abstract}
Background: Keratoconus is a progressive, bilateral, and asymmetric non-inflammatory corneal ectasia. Corneal Collagen Cross-Linking (CXL) is the only treatment option that focused on disease pathology and increasing the biomechanical rigidity of the cornea. HOAs are part of the refractive errors which deteriorate the quality of the retinal image and they are not correctable with sphere and cylinder corrections. Since HOAs can impact visual performance and contrast sensitivity; they are considered important indices in the field of quality of vision.
\end{abstract}

Aim of Study: To determine changes in ocular higher order aberrations (HOAs) after Corneal Collagen Cross Linking (CXL) for Keratoconus (KC).

Patients and Methods: This study was conducted between April 2018 and March 2019 comprising 30 keratoconic eyes of 19 patients. Patients were treated with epithelium-off CXL and evaluated at the baseline, 3 and 6 months after the procedure. The ocular HOAs were measured and analyzed using Zywave II Aberrometer.

Results: There was statistically significant improvement in Best Spectacle-Corrected Visual Acuity between the preoperative and 6-month evaluations $(p<0.05)$. HOAs at $6 \mathrm{~mm}$ were statistically significantly reduced at 6 months.

Conclusion: CXL is effective in improving HOA parameters in eyes with KC. changes in HOAs at $6 \mathrm{~mm}$ were significantly and strongly associated with the post-operative changes in BSCVA.

Key Words: Cornea - Collagen cross-linking - Keratoconus - Wavefront-HOAs.

\section{Introduction}

KERATOCONUS is a progressive, bilateral, and asymmetric non-inflammatory corneal ectasia [1] leading to irregular astigmatism, progressive myopia, and increased Higher-Order Aberrations

Correspondence to: Dr. Ahmed M. Moharam, The Department of Ophthalmology, Faculty of Medicine, Tanta University, Tanta, Egypt
(HOAs), with consequent impaired visual function [4].

The disease traditionally manifests in the 2 nd decade of life when the cornea presents an increasingly conical shape, secondary to its biomechanical instability, which leads to irregular astigmatism and subsequent reduced visual acuity [1-3] .

Conventional treatment for keratoconus includes rigid contact lens, intracorneal ring segments, and penetrating keratoplasty. In recent years, the objectives of treatment were not only improvement of visual acuity but also preventing disease progression [5]

Corneal Collagen Crosslinking (CXL) aided by photosensitized riboflavin helps stabilize progressive keratoconus and may delay the need for keratoplasty [6].

CXL is the only treatment option that focused on disease pathology and increasing the biomechanical rigidity of the cornea $[\mathbf{7 , 8 ]}$.

Higher-Order Aberrations (HOAs), one of the important subjects in the science of vision and optics, received very little attention before 2000 . However, advances in diagnostic and therapeutic methods in recent years have brought them to the attention of ophthalmologists and optometrists $[9,10]$.

As we know, HOAs are part of the refractive errors which are not correctable with sphere and cylinder corrections. They are also among errors of the optical system of the eye which can deteriorate the quality of the retinal image $[11,12]$. Since HOAs can impact visual performance and contrast sensitivity; they are considered important indices 
in the field of quality of vision and deserve attention [13-15].

\section{Aim of the work:}

The aim of the work is to determine changes in ocular Higher Order Aberrations (HOAs) after Corneal Collagen Cross Linking (CXL) for Keratoconus (KC).

\section{Patients and Methods}

Study design:

This study was a prospective interventional study. It was conducted between April 2018 and March 2019 comprising 30 eyes with keratoconus in Tanta University Hospitals. This study was performed in ethical considerations under the principles of the Helsinki Declaration and informed consent was obtained from all patients. The Ethics Committee of the Faculty of Medicine in Tanta University, Egypt, approved this study.

\section{Study population:}

Thirty eyes of 19 patients aged 18-32 years with progressive $\mathrm{KC}$ were enrolled in the study.

\section{Inclusion criteria:}

- Patients with confirmed keratoconus based on clinical and topography findings.

- Clear corneas.

- Minimal corneal thickness 400

Exclusion criteria:

- Patients with corneal opacities or scars.

- History of herpetic keratitis.

- Severe dry eye.

- Patients with previous ocular surgeries.

- Pregnancy and lactation.

Pre-operative evaluation:

- Visual acuity examination.

- Manifest Refraction Spherical Equivalent (MRSE).

- Slit lamp examination.

- Dilated fundus exam.

- Corneal topography using Orbscan IIZ and wavefront aberrometry using Zywave II.

\section{Cross linking procedure:}

The original cross-linking procedure (commonly referred to as the 'Dresden protocol') involves anesthetizing the eye, removing the central 8-
$10 \mathrm{~mm}$ of the epithelium and applying a riboflavin ophthalmic solution $0.1 \%$ to the corneal surface 30 minutes before irradiation and at 5 minutes intervals during the course of a 30 minute exposure to $370 \mathrm{~nm}$ UVA with an irradiance of $3 \mathrm{mWcm}-2$.

After cross linking, antibiotic eye drops "moxifloxacin ophthalmic solution $0.5 \%$ " were applied four times daily for 1 week. Application of topical steroid "prednisolone acetate $1 \%$ ophthalmic suspension" four times daily for 1 week then tapered over 3 weeks. A therapeutic soft contact lens with good oxygen transmissibility placed upon the eye.

\section{Post-operative evaluation:}

All patients had comprehensive ophthalmic evaluation after three months and six months including:

-Visual acuity examination.

- Manifest Spherical Equivalent (MSE).

- Slit lamp examination.

- Dilated fundus exam.

- Corneal topography using Orbscan IIZ and wavefront aberrometry using Zywave II.

\section{Statistical analysis:}

The collected data were organized, tabulated and statistically analyzed using SPSS version 19 (Statistical Package for Social Studies) created by IBM, Illinois, Chicago, USA. For numerical values the range mean and standard deviations were calculated. The differences between two mean values were used using student's $(t)$ test. For numerical data when the normal distribution was not guaranteed, Mann-Whitney test (Z) was used to compare difference in mean values instead of $(t)$ test. For categorical variable the number and percentage were calculated and differences between subcategories were tested by Monte Carlo exact test. The correlation between two variables was calculated using Pearson's correlation coefficient. The level of significant was adopted at $p<0.05$.

\section{Results}

A total of 30 eyes of 19 patients with progressive $\mathrm{KC}$ were enrolled in this study. No patients were lost to follow-up, and all patients completed the examination sessions. The mean age of the study population was $25.5 \pm 5.84$ years.

\section{Visual acuity changes:}

There was a statistically significant decrease in BSCVA in log MAR readings from the preoperative values $(p<0.05)$ as shown in (Table 1$)$. 
Table (1): Comparison between BSCVA Log MAR preoperative and 6 months post-operative.

\begin{tabular}{|c|c|c|c|c|}
\hline \multirow{2}{*}{ Groups } & \multicolumn{2}{|c|}{$\begin{array}{l}\text { BSCVA } \\
\text { Log MAR }\end{array}$} & \multirow{2}{*}{$\begin{array}{c}\text { Test of } \\
\text { significance } \\
\text { Mann- } \\
\text { whitney } \\
\text { U-test }\end{array}$} & \multirow{2}{*}{$\begin{array}{c}p- \\
\text { value }\end{array}$} \\
\hline & Range & Median & & \\
\hline - Pre-operative $(n=30)$ & $0.00-0.6$ & 0.3 & Z score & $0.01 *$ \\
\hline $\begin{array}{l}\text { - Post-operative } 6 \\
\text { months }(n=30)\end{array}$ & $0.1-1.00$ & 0.2 & 2.3 & \\
\hline
\end{tabular}

${ }^{*} p<0.05$ (statistically significant).

\section{Higher order aberrations:}

HOAs were reported for a $6 \mathrm{~mm}$ diameter. Preoperatively, the total HOAs was (range 0.35-1.56, median 0.58). At 3 months, it had reduced to (range 0.26-1.49, median 0.51). At 6 months it had significantly reduced to (range $0.19-1.38$, median 0.39 ).

Table (2): Comparison between $6 \mathrm{~mm}$ higher order aberrations pre-operative and 3 months post-operative.

\begin{tabular}{|c|c|c|c|c|}
\hline \multirow{2}{*}{ Groups } & \multicolumn{2}{|c|}{$\begin{array}{c}6 \mathrm{~mm} \text { higher } \\
\text { order aberrations }\end{array}$} & \multirow{2}{*}{$\begin{array}{c}\text { Test of } \\
\text { significance } \\
\text { Mann- } \\
\text { whitney } \\
\text { U-test }\end{array}$} & \multirow{2}{*}{$\begin{array}{c}p- \\
\text { value }\end{array}$} \\
\hline & Mean \pm SD & Range & & \\
\hline - Pre-operative $(\mathrm{n}=30)$ & $0.8 \pm 0.38$ & $0.35-1.56$ & \multirow{2}{*}{$\begin{array}{l}Z \text { score } \\
1.61614\end{array}$} & \multirow[t]{2}{*}{$0.05 *$} \\
\hline $\begin{array}{c}\text { - Post-operative } 3 \\
\text { months }(\mathrm{n}=30)\end{array}$ & $0.7 \pm 0.39$ & $0.26-1.49$ & & \\
\hline
\end{tabular}

${ }^{*} p>0.05$ (statistically insignificant).

Table (3): Comparison between $6 \mathrm{~mm}$ higher order aberrations pre-operative and 6 months post-operative.

\begin{tabular}{|c|c|c|c|c|}
\hline \multirow{2}{*}{ Groups } & \multicolumn{2}{|c|}{$\begin{array}{c}6 \mathrm{~mm} \text { higher } \\
\text { order aberrations }\end{array}$} & \multirow{2}{*}{$\begin{array}{c}\text { Test of } \\
\text { significance } \\
\text { Mann- } \\
\text { whitney } \\
\text { U-test }\end{array}$} & \multirow{2}{*}{$\begin{array}{c}p- \\
\text { value }\end{array}$} \\
\hline & Mean $\pm \mathrm{SD}$ & Range & & \\
\hline - Pre-operative $(n=30)$ & $0.8 \pm 0.38$ & $0.35-1.56$ & \multirow{2}{*}{$\begin{array}{l}Z \text { score } \\
2.63\end{array}$} & \multirow[t]{2}{*}{$0.004 *$} \\
\hline $\begin{array}{c}\text { Post-operative } 6 \\
\text { months }(n=30)\end{array}$ & $0.55 \pm 0.32$ & $0.19-1.38$ & & \\
\hline
\end{tabular}

${ }^{*} p<0.05$ (statistically significant).

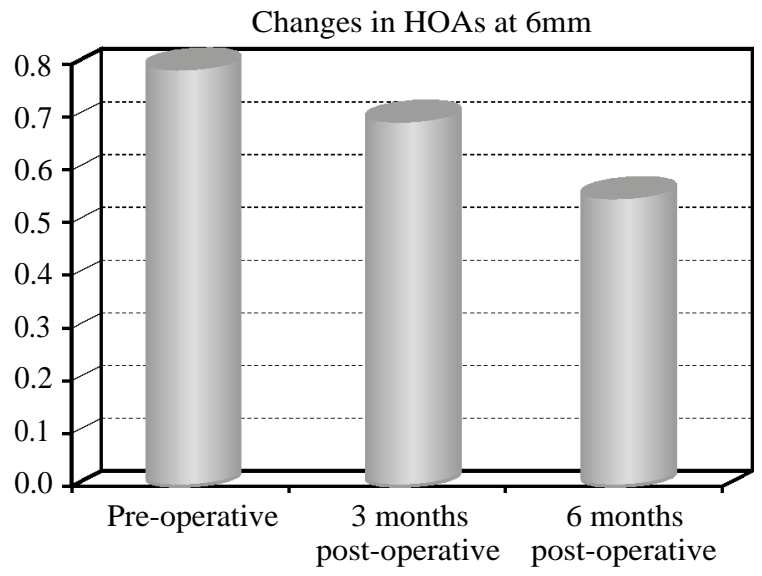

Fig. (1)

\section{Discussion}

The principal aim of this study was to determine changes in HOAs after 3 months and 6 months of corneal collagen cross linking using Epi off Dresden protocol to treat keratoconus.

In keratoconic eyes, VA was used clinically for assessing the impact of HOAs. Increased levels of HOAs introduced by $\mathrm{KC}$ lead to reduced VA. Conversely, correcting HOAs by CXL can improve visual acuity [16].

The present study revealed that there was a statistically significant improvement in the BSCVA post-operatively. The median of pre-operative BSCVA in logMAR was (0.3). Post-operative median of BSCVA at 6 months was (0.2). Changes in BSCVA after 6 months post-operative were statistically significant $(p<0.05)$.

Improvement of visual acuity has been mentioned in other CXL studies as well. Derakhshan [17] has published his results show significant improvement in UCVA and BCVA, and reduction in SE and keratometric readings. Visual improvement in most patients began after the first month, slightly increased by the third month, and remained stable until 6 months. Similarly, Vinciguerra [18] found that in patients with $\mathrm{KC}$, mean best-corrected vision ( $\log$ MAR) improved from 0.28 to 0.14 at 12 months post-operatively.

In the present study, $6 \mathrm{~mm}$ HOAs was statistically significantly reduced at 6 months. HOAs were reported for a $6 \mathrm{~mm}$ diameter; pre-operatively, the total HOAs was (range 0.35-1.56, median 0.58). At 6 months post-operative it had significantly reduced to (range 0.19-1.38, median 0.39).

Mohammad Naderan stated that CXL is effective in improving HOA parameters in eyes with progressive $\mathrm{KC}$. There were significant correlations between pre-operative measurements of HOAs parameters with best-corrected visual acuity [19]

Factors affecting the improvement in the visual acuity after corneal collagen crosslinking are not clear. We can prove that reducing higher order aberrations after corneal collagen cross linking is correlated with visual acuity improvement.

\section{Conclusion:}

There were statistically significant decreases in total HOAs at $6 \mathrm{~mm}$ readings from the preoperative values. These changes were correlated with changes in "BSCVA logMAR" and there were 
correlations indicating their effect on best spectacle corrected visual acuity.

Improvement in BSCVA was demonstrated throughout our study by statically significant decrease in BSCVA logMAR.

\section{Conclusion:}

The findings of our study reinforce what was previously known about improvements in HOA using the Zywave Aberrometer.

In keratoconic eyes, improvement in HOA profile can be considered as a mechanism to improve visual acuity.

\section{Recommendation:}

Further studies with larger samples and longer follow-up period are recommended to confirm the presented study.

\section{References}

1- RABINOWITZ Y.S.: Keratoconus. Surv. Ophthalmol., 42 (4): 297-319. doi: 10.1016/S0039-6257(97)00119-7, 1998.

2- DAVIS L.J., SCHECHTMAN K.B., WILSON B.S., ROSENSTIEL C.E., RILEY C.H., LIBASSI D.P., GUNDEL R.E., ROSENBERG L., GORDON M.O. and ZADNIK K.: Collaborative Longitudinal Evaluation of Keratoconus (CLEK) Study Group Longitudinal changes in visual acuity in keratoconus. Invest. Ophthalmol. Vis. Sci., 47 (2): 489-500. doi: 10.1167/iovs.05-0381, 2006.

3- McMAHON T.T., EDRINGTON T.B., SZCZOTKAFLYNN L., OLAFSSON H.E., DAVIS L.J. and SCHECHTMAN K.B.: CLEK Study Group Longitudinal changes in corneal curvature in keratoconus. Cornea, 25 (3): 296305. Doi: 10.1097/01.ico.0000178728.57435.df, 2006.

4- KRACHMER J.H., FEDER R.S. and BELIN M.W.: Keratoconus and related non inflammatory corneal thinning disorders. Surv. Ophthalmol., 28 (4): 293-322, 1984

5- JHANJI V., SHARMA N. and VAJPAYEE R.B.: Management of keratoconus: Current scenario. Br. J. Ophthalmol., 95 (8): 1044-50, 2011.

6- HOVAKIMYAN M., GUTHOFF R.F. and STACHS O Collagen cross-linking: Current status and future directions. J. Ophthalmol., 2012: 406850, 2012.
7- WOLLENSAK G.: Crosslinking treatment of progressive keratoconus: New hope. Curr. Opin. Ophthalmol., 17 (4): 356-60, 2006.

8- WOLLENSAK G., SPOERL E. and SEILER T.: Riboflavin/ultraviolet-a induced collagen crosslinking for the treatment of keratoconus. Am. J. Ophthalmol., 135 (5): 620-7, 2003.

9- CARVALHO L.A., CASTRO J.C. and CARVALHO L.A.: Measuring higher order optical aberrations of the human eye: Techniques and applications. Braz J. Med. Biol. Res., 35: 1395-406, 2002.

10- SALMON T.O. and VAN De POL C.: Evaluation of a clinical aberrometer for lower-order accuracy and repeatability, higher-order repeatability, and instrument myopia. Optometry, 76: 461-72, 2005.

11- HOFER H., CHEN L., YOON G.Y., SINGER B., YAMAUCHI Y. and WILLIAMS D.R.: Improvement in retinal image quality with dynamic correction of the eye's aberrations. Opt. Express, 8: 631-43, 2001.

12- THIBOS L.N.: Retinal image quality for virtual eyes generated by a statistical model of ocular wavefront aberrations. Ophthalmic Physiol. Opt., 29: 288-91, 2009.

13-YAMAGUCHI T., NEGISHI K., OHNUMA K. and TSUBOTA K.: Correlation between contrast sensitivity and higher-order aberration based on pupil diameter after cataract surgery. Clin. Ophthalmol., 5: 1701-7, 2011.

14- BUHREN J., MARTIN T., KUHNE A. and KOHNEN T.: Correlation of aberrometry, contrast sensitivity, and subjective symptoms with quality of vision after LASIK. J. Refract. Surg., 25: 559-68, 2009.

15- OSHIKA T., OKAMOTO C., SAMEJIMA T., TOKUNAGA T. and MIYATA K.: Contrast sensitivity function and ocular higher-order wavefront aberrations in normal human eyes. Ophthalmology, 113: 1807-12, 2006.

16- APPLEGATE R.A., MARSACK J.D. and RAMOS R.: Interaction between aberrations to improve or reduce visual performance. J. Cataract. Refract. Surg., 29 (8): 1487-95, 2003.

17- DERAKHSHAN A., HERAVIAN SHANDIZ J. and AHADI M.: Short-term outcomes of collagen crosslinking for early keratoconus. J. Ophthalmic. Vis. Res., 6 (3): 1559, 2011.

18- VINCIGUERRA P., ALBÈ E., TRAZZA S., et al.: Refractive, topographic, tomographic, and aberrometric analysis of keratoconic eyes undergoing corneal cross-linking. Ophthalmol., 116 (3): 369-78, 2009.

19- NADERAN M. and JAHANRAD A.: Higher-order aberration 4 years after corneal collagen cross-linking. Indian Journal of Ophthalmology, Sep., 65 (9): 808-12, 2017. 


\section{تغيرات إنحرافات العين ذات الترتيبات العليا

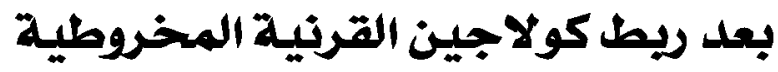

فى المرضى الذين يعانون من القرنية المخرطية، فإن سطح القرنية الآمامى هو آهم مصدر للإنصرافات البصرية. وتفيد التقارير آنه فى إنى

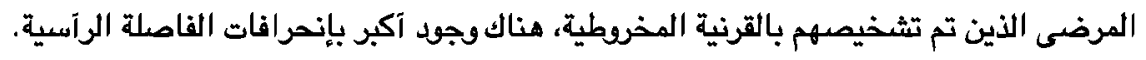
يستخدم مجسمات مقدمة الموجة لقياس الحالة الإنكسارية الكاملة، بما في ذلك الإستجماتيزم غير المنتظم في النظام البصرى. الهدف من البحث: الهدف من الدراسة هو تحديد تفيرات إنحرافات العين ذات الترتيبات العليا بعد ربط كولاجين القرنية المخرطية.

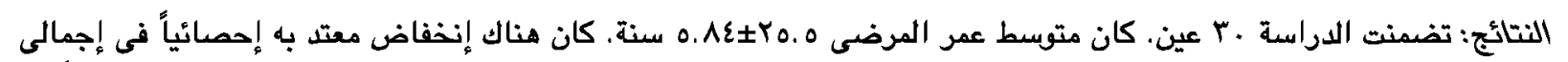

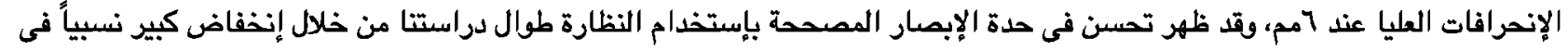
.BSCVA logMAR

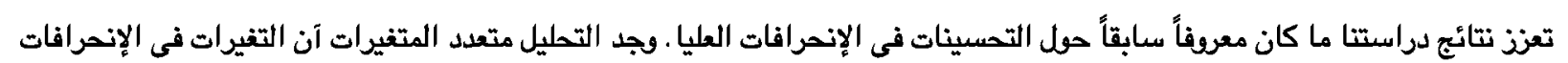

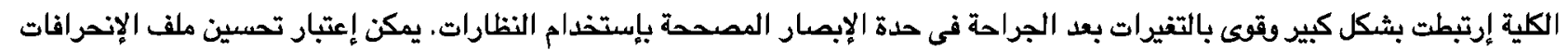
العليا كآلية لتحسين الوظيفة البصرية في بالئفيرات العيون ذات القرنية المخرطية. 